\title{
New Method for Evaluation of Radial Crush Strength of Paper Cores
}

\author{
Z. KOLAKOWSKI*, W. SZEWCZYK**, M. BIEŃKOWSKA***, L. CZECHOWSKI**** \\ *Lodz University of Technology, Department of Strength of Materials, ul. Stefanowskiego 1/15, 90-924 Łódź, Poland, \\ E-mail: zbigniew.kolakowski@p.lodz.pl \\ **Lodz University of Technology, Institute of Papermaking and Printing, ul. Wólczańska 223, 90-924 Łódź, Poland, \\ E-mail: wlodzimierz.szewczyk@p.lodz.pl \\ ***Lodz University of Technology, Institute of Papermaking and Printing, ul. Wólczańska 223, 90-924 Łódź, Poland, \\ E-mail: maria.bienkowska@p.lodz.pl \\ ****Lodz University of Technology, Department of Strength of Materials, ul. Stefanowskiego 1/15, 90-924 Lódź, Poland, \\ E-mail: leszek.czechowski@p.lodz.pl
}

cross $^{\text {ref }}$ http://dx.doi.org/10.5755/j01.mech.24.2.18444

\section{Introduction}

Paper cores are now commonly used for winding foils, papers and fabrics, but also as thermometer covers in the metallurgical industry or construction materials for packaging and building sectors. They are produced using two methods. The first one is based on parallel winding (Fig. 1, a), the other one on spiral winding (Fig. 1, b) [1].

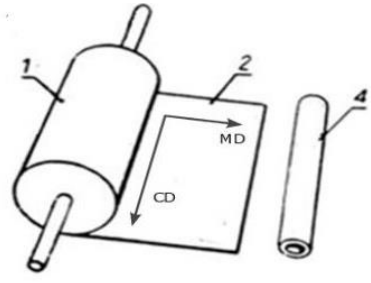

a

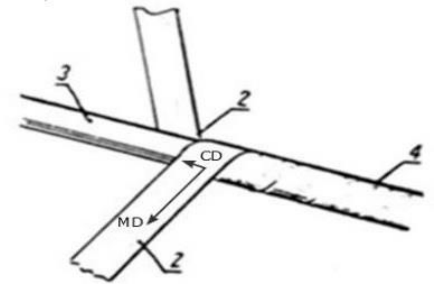

$\mathrm{b}$

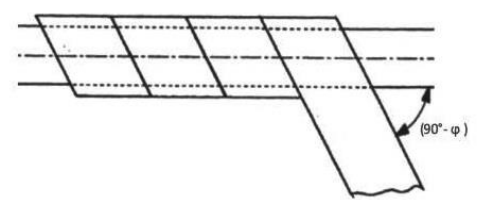

C

Fig. 1 Paper cores making: 1 - paper roll, 2 - paper sheet, 3 - spindle, 4 - core

Depending on how the cores are used, they are subjected to a variety of loads, and therefore their mechanical properties are important. One of the most common core stresses is crushing with radial forces. To evaluate the core strength to this type of load, a compression test is applied to compress the load uniformly along two opposite generating lines [2] (Fig. 2), defined in ISO 11093-9: 2006 as radial crushing $[3,4]$. Measurement methods are very useful for evaluating the produced cores, but in the preparation phase of production the methods of predicting their strength properties are more useful. When calculating the strength of a spirally wound core, the problem is complicated by the fact that their walls are made of a laminate whose individual layers are papers of different thicknesses and mechanical properties. In addition, the distribution of these properties in the plane of the paper is a characteristic distribution for orthotropic bodies with major orthotropic axes associated with the machine direction MD (direction of paper production) and the cross direction $\mathrm{CD}$. In parallel wound cores, one of the main orthotropy axes is parallel to the generating line and the other is perpendicular to it. In spirally wound cores the main orthotropy axes of the mechanical properties of the paper are arranged at an angle $\left(90^{\circ}-\varphi\right)$ to the longitudinal axis of the core (Fig. 1, c).

Numerical calculation methods currently used [58] are complicated, time-consuming and require the use of expensive hardware and software and they are therefore not used in industrial practice. At the same time, there are no easy to use analytical and empirical dependencies to predict the strength of paper cores.

The aim of this article is to present a new, simple method for assessment of the radial crushing resistance of paper-cores winded up spirally.

\section{Methods and results}

Preparation of the mathematical model for evaluating the crush resistance of paper cores presented in this article was based on the permissible stress method (so-called bottom estimate) described in [9-13]. The proposed method of calculations is based on the theory of multilayered composite beams [9, 14, 15].

Numerous radial compression tests of paper cores showed that the cores deform symmetrically to the surface of any cross-section perpendicular to the longitudinal axis of the core and each cross section is the same, corresponding with hypothesis of the flat cross sections [11-13, 17]. Therefore, the conditions for continuity of deformation in the direction of the longitudinal axis of the paper core.

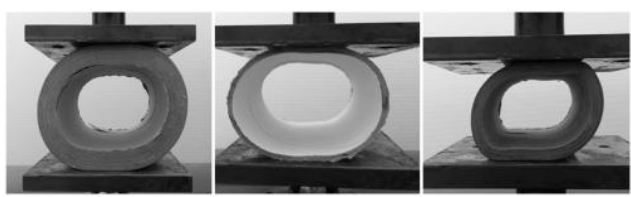

Fig. 2 Cross section of crushed core

Due to the above-mentioned assumptions, radically compressed with force $P$, the roll core with length $L$ (Fig. 3) can be treated as a pipe loaded with continuous linear load of value $q=P / L$.

This article discusses paper cores whose individual layers are made of papers of different thickness and properties with MD machine direction in the paper is inclined at an angle $\varphi$ to the direction perpendicular to the generating 
line of the roll, i.e. at an angle $\left(90^{\circ}-\varphi\right)$ to the longitudinal axis of the core. Such structure of the core requires the application of the classical theory of multi-layer composites [4- 6, 10,11], according to which there are coupled interactions between matrices of longitudinal stiffness $A$, bending stiffness $D$ and coupling rigidity (or so-called interactions) $B$. This makes it necessary to include rigidity in the analysis of all these matrices and to estimate their effect on the final results. Due to the complexity of these derivations, only final formulas are given, which are a modification of the analogical formulas presented in the paper [4], taking into account the classical theory of laminates (composites).

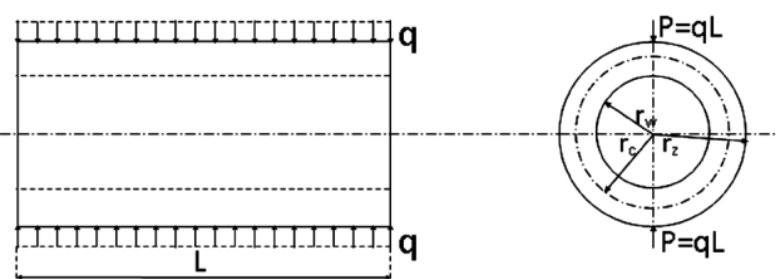

Fig. 3 Core loading model in a flat bending test

The applied composite theory for beams requires introduction of determinants and auxiliary values shown in Appendix. According to the theory of strongly curved rods, known in the strength of materials, for the cross section of the paper core (Fig. 2) the $[4,7-9,13]$ were introduced:

$$
r_{c} /\left(r_{z}-r_{w}\right)=r_{c} / h
$$

where: $r_{z}=r_{w}+h, r_{c}=\left(r_{w}+r_{z}\right) / 2$ is the radius of pipe curve, whereas $h$ is defined by formula (A1).

Due to the value of ratio $r_{c} / h$ we can determine maximal bending stress of composite paper core from the following relationships:

1. for $r_{c} / h \geq 10$ (as for a straight composite beam):

$$
\sigma_{g \max }=\frac{q E_{n}^{\phi} r_{c}}{E_{e f}^{\phi} \pi} \frac{6}{h^{2}} \leq f_{0 n}^{\phi},
$$

2. for $2 \leq r_{c} / h \leq 10$ :

$$
\sigma_{\text {gmax }}=\frac{q E_{n}^{\phi} r_{c}}{E_{e f}^{\phi} \pi} \frac{\left(r_{c}-e-r_{w}\right)}{h e r_{w}} \leq f_{0 n}^{\phi},
$$

where:

$$
e=h^{2} /\left(12 r_{c}\right)
$$

Relationship (1) and relationship (2) can be simplified by introducing - in accordance with (A6) - the average value of the compressive strength of the paper in the circumferential direction $f_{\mathrm{O} e f}^{\varphi}$ and assuming real (i.e. measured) core dimensions $r_{z r}, h_{r}$ and assuming, that $E_{n}^{\varphi} / E_{e f}^{\varphi}=1$. Then the formulas (1) and (2) will take form of (5) and (7) respectively:
1. for $r_{c r} / h_{r} \geq 10$ (as for a straight beam):

$$
\sigma_{g \max }=\frac{q r_{c r}}{\pi} \frac{6}{h_{r}^{2}} \leq f_{0 e f}^{\phi},
$$

where: $r_{z r}=r_{w}+h_{r}$,

$$
r_{c r}=\left(r_{w}+r_{z r}\right) / 2
$$

2. for $2 \leq r_{c r} / h_{r} \leq 10$ :

$$
\sigma_{g \max }=\frac{q r_{c r}}{\pi} \frac{\left(r_{c r}-e_{r}-r_{w}\right)}{h_{r} e_{r} r_{w}} \leq f_{0 e f}^{\phi},
$$

where:

$$
e_{r}=h_{r}^{2} /\left(12 r_{c r}\right)
$$

By converting relationships (1), (2), (4) and (6), four values of the radial crush strength of the core can be determined. They were marked as follows $q_{1}=P_{1} / L$, $q_{2}=P_{2} / L, q_{4}=P_{4} / L$ and $q_{6}=P_{6} / L$.

The radial crush tests of 12 multi-layered cores, spirally wound, with different geometrical parameters as shown in Table 1 were conducted.

Table 1

Geometric parameters of tested cores

\begin{tabular}{|c|c|c|c|c|}
\hline \multirow{2}{*}{ Core } & \multirow{2}{*}{$\begin{array}{c}\text { Internal ra- } \\
\text { dius, } r_{w} \\
\end{array}$} & \multicolumn{2}{|c|}{$\begin{array}{c}\text { Wall thickness of the } \\
\text { core }\end{array}$} & \multirow{2}{*}{$r_{c} / h$} \\
\cline { 3 - 4 } & & $h[\mathrm{~mm}]$ & $h_{r}[\mathrm{~mm}]$ & \\
\hline T1 & 38 & 5,25 & 5,5 & 7,6 \\
\hline T2 & 25 & 3,65 & 3,5 & 7,3 \\
\hline T3 & 20 & 4,05 & 4,0 & 5,4 \\
\hline T4 & 38 & 4,77 & 5,0 & 8,5 \\
\hline T5 & 38 & 7,89 & 8,0 & 5,3 \\
\hline T6 & 38 & 8,74 & 9,0 & 4,8 \\
\hline T7 & 38 & 12,83 & 13,0 & 3,4 \\
\hline T8 & 17 & 1,32 & 1,47 & 13,0 \\
\hline T9 & 17 & 1,30 & 1,43 & 13,3 \\
\hline T10 & 25 & 5,761 & 5,75 & 4,9 \\
\hline T11 & 38 & 3,106 & 3,17 & 12,8 \\
\hline T12 & 125 & 7,60 & 7,95 & 17,1 \\
\hline
\end{tabular}

The papers for core component layers were subjected to the tensile strength test, based on which Young's modulus and the short-span compressive test (SCT) were determined. All measurements were made in the circumferential direction, i.e. in the direction angled to the machine direction MD.

In order to avoid the influence of moisture on the test results, the cores and papers were air conditioned at $23 \pm 1{ }^{\circ} \mathrm{C}$ and $50 \pm 2 \% \mathrm{RH}$ in accordance with PN-EN 20187: 2000.

\section{Results and discussion}

A summary of the measurement and calculation results of the core crush strength is shown in Table 2. In the 
case of core T12, delamination was observed already in the initial phase of the crushing test (Fig. 4). This phenomenon was not apparent in the case of crushing of the remaining cores (Fig. 5). Because in the modeling, the core was treated as homogeneous non-delaminated, core T12 was omitted in further analysis. Additionally, Table 1 shows the number of layers $n$ of the paper cores, bending stiffness in the circumferential direction $D_{11}^{\varphi}$ (A2) and stiffness reduction factor $\alpha^{\varphi}(\mathrm{A} 4)$.

Summary of measurement and calculation

Table 2 results of radial crush strength

\begin{tabular}{|c|c|c|c|c|c|}
\hline \multirow{2}{*}{ Core } & \multicolumn{5}{|c|}{ Radial crush resistance [N/m] } \\
\cline { 2 - 6 } & $q_{1}$ & $q_{2}$ & $q_{4}$ & $q_{6}$ & $\begin{array}{c}\text { Measure- } \\
\text { ment }\end{array}$ \\
\hline T1 & 425 & 4067 & 3796 & 3619 & 6022 \\
\hline T2 & 226 & 2154 & 1938 & 1852 & 2851 \\
\hline T3 & 354 & 3324 & 3381 & 3169 & 4803 \\
\hline T4 & 337 & 3236 & 3760 & 3602 & 5402 \\
\hline T5 & 844 & 7902 & 9104 & 8507 & 9589 \\
\hline T6 & 102 & 9559 & 1134 & 1051 & 10378 \\
\hline T7 & 206 & 1853 & 2260 & 2029 & 17054 \\
\hline T8 & 856 & 834 & 918 & 891 & 1650 \\
\hline T9 & 620 & 604 & 711 & 691 & 1777 \\
\hline T10 & 880 & 8187 & 7481 & 6955 & 8980 \\
\hline T11 & 159 & 1550 & 1963 & 1911 & 4002 \\
\hline T12 & 309 & 3036 & 3393 & 3323 & 2530 \\
\hline
\end{tabular}

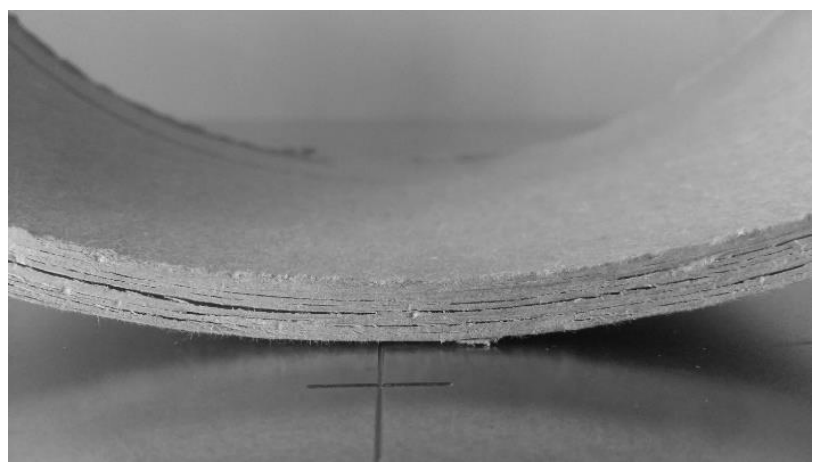

Fig. 4 Delamination of core T12

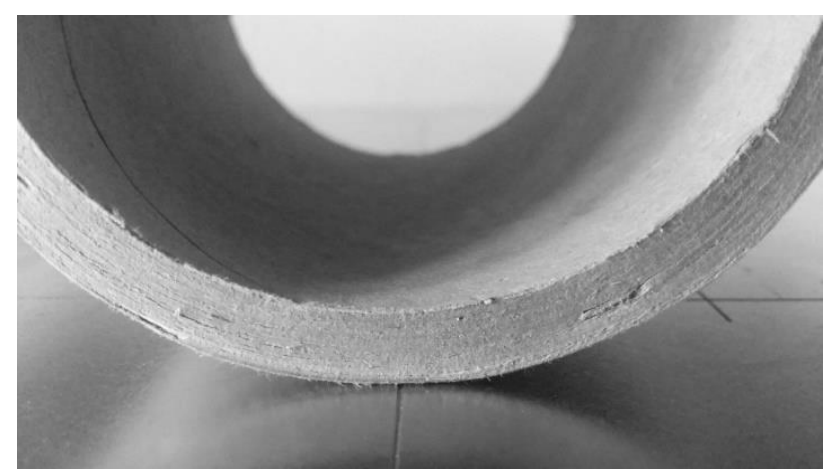

Fig. 5 An example of a non-delamination core

The results of the measurements and calculation of the core radial crush strength are shown in Fig. 6. In order to analyze the differences between the measurement and calculation results, index $\Delta q_{i}$ was introduced, expressed by the relationship:

$$
q_{i}=\frac{q_{i}-q_{i z}}{q_{i z}} 100 \%,
$$

where: $q_{i}$ is theoretic value, $q_{i z}$ is measured value, $i=1,2,4$, $6)$ expressing in percentage the difference between the measured and calculated value in relation to the measured value.

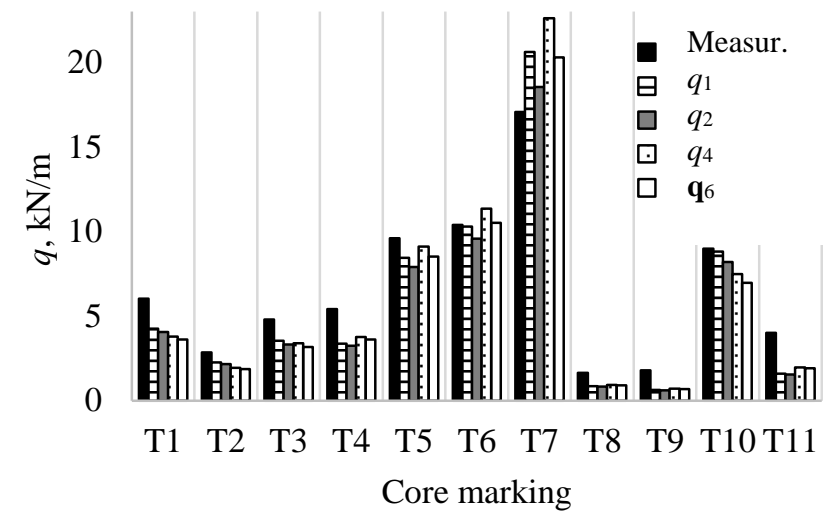

Fig. 6 List of calculated and measured values of core radial crush resistance

Figs. 7-10 show the values of $\Delta q_{i}$ in function $r_{c} / h$. The index at $\Delta q_{i}$ is the number of the formula from which the theoretical value is calculated.

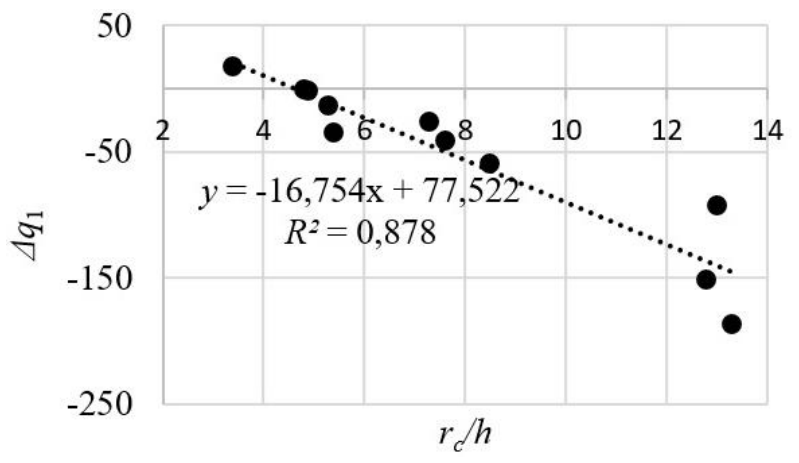

Fig. 7 Differences in the values of actual destructive forces and forces calculated with formula (1)

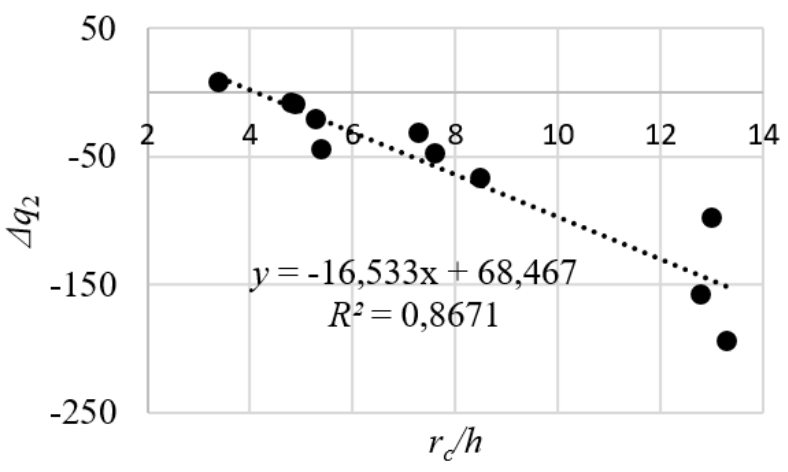

Fig. 8 Differences in the values of actual destructive forces and forces calculated with formula (2) 


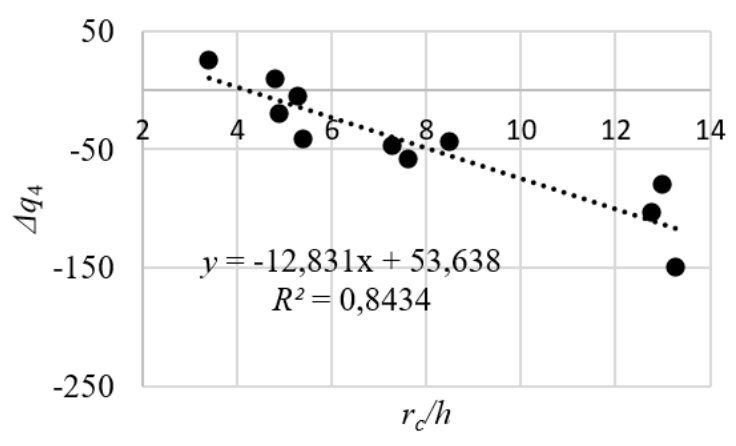

Fig. 9 Differences in the values of actual destructive forces and forces calculated with formula (4)

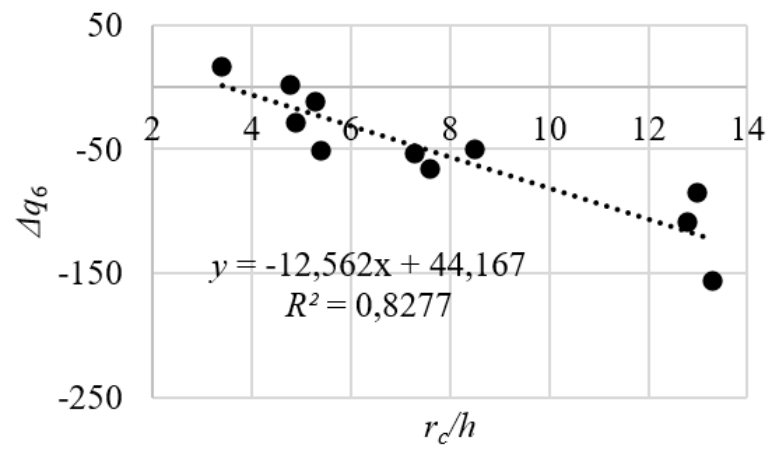

Fig. 10 Differences in the values of actual destructive forces and forces calculated with formula (6)

All diagrams show a similar relationship, with an increase in the $r_{c} / h$ value, the value of $\Delta q_{i}$ decreases, which can be roughly described as a linear relationship. An equation describing a trend line depicting the aforementioned relationships were used to determine the coefficient for correcting the values of the destructive forces calculated on the theoretical basis.

The corrected value of force $q_{i}$ marked as $q^{\prime}$ was calculated from the relationship:

$$
q^{\prime}=\left[1-a\left(r_{c} / h\right)-b\right] q_{i}\left(r_{c}, h, \ldots\right),
$$

where: $q_{i}\left(r_{c}, h, \ldots\right)$ is selected relationship describing the force value before correction, $a, b$ are coefficients of the trend line equation based on the results of measurements and calculations (Figs. 7-10).

Correcting the relationships (1), (2), (4) and (6) according to formula (9), the calculations were made, the results of which are shown in Fig. 11.

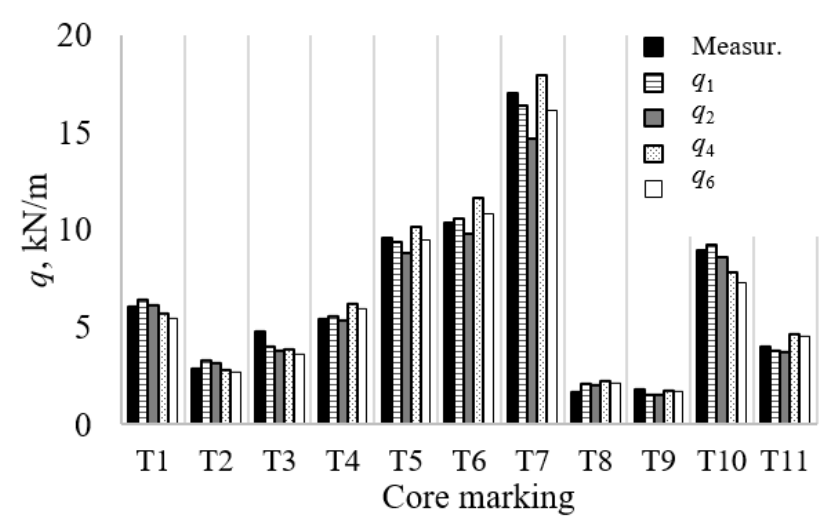

Fig. 11 Summary of values of destructive forces measured and calculated taking into account correlations

\section{Conclusions}

Simple mathematical models proposed for calculating the radial crush strength of spirally wound cores can be used if their strength properties are not affected by defects such as: for example, incorrect gluing, resulting in delamination of the walls.

The smallest discrepancies between the results of measurements and calculations made with the relationships corrected with formula (9) and shown in Fig. 11 were obtained using formula (1). They are within $+/-20 \%$ of the measured values. For the remaining relationships, the scatter value was slightly higher from $-28 \%$ to $+18 \%$ for relationship (2), $-26 \%$ to $+25 \%$ for relationship (4) and $+/-23 \%$ for relationship (6).

\section{References}

1. Stera, S. 1998. Paper finishing machines. Wydawnictwo Politechniki Łódźkiej.

2. Kołakowski, Z.; Szewczyk, W.; Lapczyńska, M. 2014. Mechanical properties of paper cores. Part III. Flat crush resistance. Przegląd Papierniczy, 70: 459462.

3. Pearson, J. 1991. Sonoco aims to make a better core, Pulp Paper Int. 33, 1, 55.

4. ISO11093-9:2006. Paper and board - Testing of cores Part 9: Determination of flat crush resistance.

5. Bolzon, G.; Talassi, M. 2014. A combined experimental and numerical study of the behaviour of paperboard composites up to failure, Composites: Part B; 66: 358-367. https://doi.org/10.1016/j.compositesb.2014.05.023.

6. Fadiji, T.; Coetzee, C.; Opera, U.L. 2016. Compression strength of ventilated corrugated paperboard packages: Numerical modelling, experimental validation and effects of vent geometric design, Biosystems Engineering; 151: 231-247. https://doi.org/10.1016/j.biosystemseng.2016.09.010.

7. Hou S, Shu Chu, Zhao S, Liu T, Han X, Li Q. 2015. Experimental and numerical studies on multi-layered corrugated sandwich panels under crushing loading, Composite Struct; 126: 371-385. https://doi.org/10.1016/j.compstruct.2015.02.039.

8. Nunes, F.; Correia, M.; Correia, J.R.; Silvestre, N.; Moreira, A. 2013. Experimental and numerical study on the structural behaviour of eccentrically loaded GFRP columns. Thin-Walled Struct; 72: 175-87. https://doi.org/10.1016/j.tws.2013.07.002.

9. Kolakowski, Z. 2008. Strength and Stability of plate composite structures - basic, Lodz University of Technology Publishing. (http://hdl.handle.net/11652/1476).

10. Jones, R.M. 1999. Mechanics of Composite Materials; 2nd ed. Taylor \& Francis, London.

11. Jakubowicz, A.; Orłoś, Z. 1978. Strength of Materials, WNT.

12. Niezgodziński, M. E.; Niezgodziński, T. 2009. Strength of materials, PWN.

13. Timoshenko, S. 1930. Strength of materials. Part I and II. Van Nostrand Company, New York.

14. Altenbach, H.; Altenbach, J.; Kissing, W. 2001. Structural analysis of laminate and sandwich beams and 
plates. An Introduction into the Mechanics of Composite, Lubelskie Towarzystwo Naukowe.

15. Altenbach, H.; Altenbach, J.; Kissing, W. 2004. Mechanics of Composite Structural Elements. SpringerVerlag Berlin Heidelberg.

https://doi.org/10.1007/978-3-662-08589-9.

16. Carlsson, L.A.; Byron Pipes, R. 1997. Experimental characterization of advanced composite materials. Lancaster, Bassel.

17. Gere, J.M. 2004. Mechanics of Materials (Six Edition). Brooks/Cole-Thomson Learning, Inc., Belmont USA.

\section{Appendix}

The application of composite theory for beams requires the introduction of auxiliary values. The total thickness of the paper core is:

$$
h=\sum_{i=1}^{n} h_{i}
$$

where: $h$ is core nominal thickness, $h_{i}$ is thickness of $i^{\text {th }}$ layer of paper, $n$ is number of paper layers of the core.

Values of longitudinal stiffness matrix $A_{11}^{\varphi}$, bending stiffness $D_{11}^{\varphi}$ and coupling $B_{11}^{\varphi}$ in the circumferential direction ((i.e. at an angle $\varphi$ to the machine direction MD of core papers) can be determined from the dependence:

$$
\begin{aligned}
A_{11}^{\phi} & =\sum_{i=1}^{n} E_{i}^{\phi}\left(z_{i}-z_{i-1}\right) \\
D_{11}^{\phi} & =\frac{1}{3} \sum_{i=1}^{n} E_{i}^{\phi}\left(z_{i}^{3}-z_{i-1}^{3}\right) \\
B_{11}^{\phi} & =\frac{1}{2} \sum_{i=1}^{n} E_{i}^{\phi}\left(z_{i}^{2}-z_{i-1}^{2}\right)
\end{aligned}
$$

where: $z_{0}=-h / 2 ; z_{1}=-h / 2+h_{1} ; z_{2}=-h / 2+h_{1}+h_{2} ; \ldots$ $z_{n}=+h / 2$. Number of a layer $i=1$ corresponds with the external layer of the core, $n$ internal layer, whereas $E_{i}^{\varphi}$ is Young modulus of $i$ - $^{\text {th }}$ paper layer in circumferential direction of the core. The effective Young's replacement modulus in the circumferential direction of the core (i.e. at an angle $\varphi$ ) can be determined from the following formula:

$$
E_{e f}^{\phi}=\frac{12}{h^{3}} D_{11}^{\phi} \alpha^{\phi}
$$

where:

$$
\alpha^{\phi}=1-\left(B_{11}^{\phi}\right)^{2} /\left(A_{11}^{\phi} D_{11}^{\phi}\right)
$$

In the same way as in [4] the SCT indicator for the paper layer from which the crushed paper core is made can be considered as the compressive strength of the paper in the circumferential direction,

$$
f_{0 n}^{\phi}=S C T_{n}^{\phi} / h_{n},
$$

where: $h_{n}, S C T_{n}^{\varphi}$ are means, respectively, the thickness and SCT index of the $n^{\text {th }}$ inner layer of the paper web at an angle $\varphi$. The concept of average value of the compressive strength of the paper in the circumferential direction, which according to (A5) is given by the formula:

$$
f_{0 e f}^{\phi}=\frac{1}{h} \sum_{i=1}^{n} f_{0 i}^{\phi}\left(z_{i}-z_{i-1}\right)
$$

Stiffness of tested paper cores

\begin{tabular}{|c|c|c|c|}
\hline \multirow{2}{*}{ Core } & $\begin{array}{c}\text { No. of paper } \\
\text { layers of the } \\
\text { core } n\end{array}$ & $D_{11}^{\varphi}(\mathrm{A} 2)$ & $\alpha^{\varphi}(\mathrm{A} 4)$ \\
\cline { 3 - 4 } & 9 & $0,343110^{5}$ & 0,9992 \\
\hline T1 & 7 & $0,910910^{4}$ & 0,9992 \\
\hline T2 & 7 & $0,144910^{5}$ & 0,9999 \\
\hline T3 & 9 & $0,242810^{5}$ & 0,9993 \\
\hline T4 & 12 & $0,103710^{6}$ & 0,9995 \\
\hline T5 & 13 & $0,141910^{6}$ & 0,9992 \\
\hline T6 & 17 & $0,436510^{6}$ & 0,9992 \\
\hline T7 & 4 & $0,696410^{3}$ & 0,9976 \\
\hline T8 & 5 & $0,503710^{3}$ & 0,9991 \\
\hline T9 & 9 & $0,429010^{5}$ & 0,9852 \\
\hline T10 & 7 & $0,941810^{4}$ & 0,9993 \\
\hline T11 & 10 & $0,839510^{5}$ & 1,0 \\
\hline T12 & & & \\
\hline
\end{tabular}

Z. Kołakowski, W. Szewczyk, M. Bieńkowska, L. Czechowski

\section{NEW METHOD FOR EVALUATION OF RADIAL CRUSH STRENGTH OF PAPERE CORES}

\section{S u m m a r y}

This article describes a new method for evaluation of radial crush strength of paper cores. Based on the theory of multilayered composites, a mathematical model has been developed to calculate the value of destructive force during radial crushing of spirally shaped paper cores whose layers are made of different materials. To start calculations, it is necessary to have geometry parameters of the cores, Young's modulus and SCT of an individual component layers.

Keywords: paper cores, radial crush strength.

Received September 18, 2017 Accepted April 18, 2018 